Category: Simulation and Skills competency

\title{
Qualitative study on the lifelong learning orientation of pharmacy graduates
}

\author{
Keng, P.S., Er, H.M., Nadarajah, V.D. \\ International Medical University, Malaysia
}

\section{Background:}

Lifelong learning is an essential skill of 21st century learners and healthcare practitioners in view of exponential knowledge growth and rapid technology advances. It is a process of acquiring knowledge and learning new skills throughout one's life to enhance personal and professional growth. The present study aimed to explore the perception and practice of lifelong learning by pharmacy graduates.

\section{Methods:}

A qualitative approach was used to gain an in-depth understanding of the lifelong learning orientation of pharmacy graduates. Ten semi-structured interviews were conducted among the pharmacy graduates from the School of Pharmacy, International Medical University. They have working experience ranging from 1 to 6 years after graduation. The interviews were transcribed and independently coded by two researchers. They were subsequently thematically analysed using an inductive approach.

\section{Results and Discussion:}

The interviewees agreed on the importance of lifelong learning in their respective professional practice. Their inputs are categorised into four themes, which are adaptation to change, personal and professional growth, social interaction, and support system. The skills should be inculcated through the teaching and learning activities during the undergraduate education. Upon graduation, the graduates need to adapt to the new roles and changes at workplace. This is achieved through participation at relevant continual professional development courses including conferences, with support provided by the employers and professional bodies. The social networking opportunities at these professional events enriches the professional experience.

\section{Conclusions:}

Pharmacy graduates perceive that lifelong learning skills are important for their career development. It is their professional commitment to constantly update their knowledge and skills to cope with the rapidly changing pharmacy employment landscape and expectations. Support from professional bodies and employers is necessary to ensure continual development of their technical and non-technical competencies.

Keywords: Lifelong learning 